Universidade de São Paulo Faculdade de Medicina de Ribeirão Preto
2019

\section{AVALIAÇÃO CLÍNICA DA INTEGRIDADE SOMATOSSENSORIAL EM INDIVÍDUOS COM DOR NO OMBRO E UM GRUPO CONTROLE}

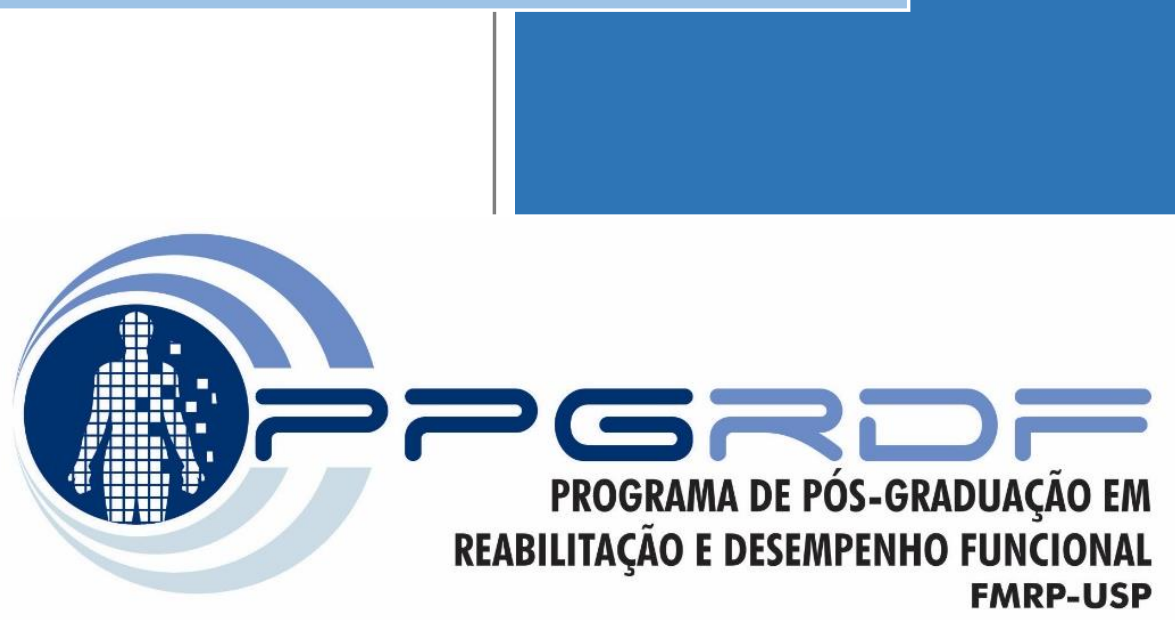

Amanda Matias Barbosa

Dissertação 


\author{
Universidade de São Paulo \\ Faculdade de Medicina de Ribeirão Preto
}

AMANDA MATIAS BARBOSA

\title{
Avaliação clínica da integridade somatossensorial em indivíduos com dor no ombro e um grupo controle.
}

Dissertação apresentada para o Programa de Pós-Graduação em Reabilitação e Desempenho Funcional da Faculdade de Medicina de Ribeirão Preto FMRP/USP como requisito parcial para obtenção do título de Mestre em Ciências.

Área de concentração: Fisioterapia

Orientadora: Profa. Dra. Anamaria Siriani de Oliveira

Colaborador: Prof. Dr. Felipe José Jandre dos Reis 
Autorizo a reprodução e divulgação total ou parcial deste trabalho, por qualquer meio convencional ou eletrônico, para fins de estudo e pesquisa, desde que citada a fonte.

Catalogação da Publicação

Faculdade de Medicina de Ribeirão Preto da Universidade de São Paulo

Barbosa, Amanda Matias

Avaliação clínica da integridade sotamossensorial em indivíduos com dor no ombro e um grupo controle. Ribeirão Preto, 2019.

47 p.: il. 3;

Dissertação de Mestrado, apresentada à Faculdade de Medicina de Ribeirão Preto/USP. Área de concentração: Fisioterapia.

Orientadora: Siriani de Oliveira, Anamaria.

1. Dor de ombro. 2. Dor Crônica 3. Percepção de dor. 4. Medição da dor. 5. Sensibilização do sistema nervoso central. 


\author{
Universidade de São Paulo \\ Faculdade de Medicina de Ribeirão Preto
}

AMANDA MATIAS BARBOSA

\title{
Avaliação clínica da integridade somatossensorial em indivíduos com dor no ombro e um grupo controle.
}


Amanda Matias Barbosa

Avaliação clínica da integridade somatossensorial em indivíduos com dor no ombro e um grupo controle.

Dissertação apresentada ao Programa de Pós-Graduação em Reabilitação e Desempenho Funcional da Faculdade de Medicina de Ribeirão Preto da Universidade de São Paulo para obtenção do título de Mestre.

Aprovado em:

Banca examinadora

Prof. Dr. Instituição:

Julgamento: Assinatura:

Prof. Dr. Instituição:

Julgamento: Assinatura:

Prof. Dr. Instituição:

Julgamento: Assinatura: 


\section{DEDICATÓRIA}

Aos meus pais, ao meu irmão e ao meu namorado que com muito carinho e apoio não mediram esforços para que eu chegasse até essa etapa da minha vida. 


\section{Agradecimentos}

A Deus que tem iluminado o meu caminho durante esta caminhada.

A toda a minha família que sempre apoiou meus estudos incentivando e possibilitando o meu aprimoramento profissional. Além de todas as palavras de conforto, conselhos e muito amor. Só tenho a agradecer por ter uma família incrível.

A Profa. Dra. Anamaria Siriani de Oliveira por toda a orientação, por ter me aberto tantas portas e possibilitar que eu integrasse a equipe do ombro. Um exemplo de professora, educadora e gestora, capaz de se reinventar e inovar nas diversas situações e de uma inteligência gigante que tive a oportunidade de aprender tanto, com certeza um exemplo que levarei para a vida toda. Muitas experiências e vivências as quais lembrarei com muito carinho e com muita gratidão.

Ao Prof. Dr. Felipe Jose Jandre dos Reis por ter co-orientado o projeto de pesquisa e que mesmo distante fisicamente se fez muito presente em todo o processo de orientação. Nesse momento só tenho a agradecer por toda a ajuda que foi fundamental, por tanta consideração em vir para Ribeirão Preto tantas vezes e nos incluir nas suas pautas. Que privilégio conhecer um grande nome da fisioterapia e de perto admirar tamanha competência.

Aos colegas de laboratório, em especial a Marília Caseiro, pela parceria durantes esses dois anos, por compartilhar dúvidas e certezas. Ter alguém bem de perto deixou o trajeto leve e divertido. Gratidão.

A Universidade de São Paulo pela oportunidade de compor toda a minha formação profissional, por todos os incentivos e conhecimento técnico, científico, trazendo ensino e qualidade na minha prática. E por ter me acolhido durante 9 anos da minha vida, por possibilitar que eu conhecesse grandes amigos, crescer tanto como pessoa e poder lembrar de tantos momentos gratificantes e especiais nesse campus. 


\section{RESUMO}

BARBOSA, Amanda Matias. Avaliação clínica da integridade somatossensorial em indivíduos com dor no ombro e um grupo controle. 2019. 47 p. Dissertação (Mestrado). Faculdade de Medicina de Ribeirão Preto - Universidade de São Paulo, Ribeirão Preto, 2019.

Nos distúrbios musculoesqueléticos, a queixa mais frequente é a dor sendo os distúrbios do ombro extremamente comuns, caracterizados por alta incidência na população, alto custo e impacto negativo nos aspectos funcionais. Considerada um problema mundial, a dor crônica acomete cerca de 60 milhões de pessoas, o que corresponde a $10 \%$ da população mundial. A reorganização da representação específica da região do corpo no córtex somatossensorial primário foi identificada como uma das alterações em diferentes populações de dor crônica. Assim, testes de avaliação da integridade somatossensorial como o teste de julgamento de lateralidade e discriminação de dois pontos são necessários para complementar a avaliação clínica para posterior planejamento de um programa de reabilitação de indivíduos portadores de dor crônica. Objetivo: comparar os resultados dos testes de julgamento de lateralidade e discriminação de dois pontos entre indivíduos com dor crônica unilateral não traumática no ombro e um grupo controle. Acredita-se que indivíduos com dor crônica no ombro apresentem maior tempo de resposta e menor porcentagem de acerto na tarefa de julgamento da lateralidade bem como discriminem a percepção de dois pontos de estímulos táteis a uma maior distância quando comparados ao grupo controle. Materiais e métodos: os voluntários foram submetidos ao teste de julgamento de lateralidade pelo aplicativo Recognise Shoulder ${ }^{T M}$ e teste de discriminação de dois pontos utilizando o paquímetro digital Mitutoyo®. Também foram questionados quanto a área dolorosa, afetividade e funcionalidade a fim de caracterização da amostra.

Resultados: Foram avaliados 52 indivíduos sintomáticos sendo 37 mulheres e 15 homens com média de idade de 54,1 $\pm 9,25$ anos, tempo médio de sintoma 40,56 \pm 39,93 meses e acometimento maior do lado direito. $\mathrm{E}$ indivíduos assintomáticos: 37 mulheres e 13 homens, sem queixa de dor no ombro, com média de idade de 44,98 $\pm 11,75$ anos, sendo a grande maioria destro. Conclusão: Existe diferença no teste de discriminação de dois pontos para uma região específica do ombro e para o tempo de resposta do teste de julgamento de lateralidade para o segmento ombro entre indivíduos com dor crônica no ombro e um grupo controle. 
Palavras Chave: dor de ombro, dor crônica, percepção de dor, medição da dor, sensibilização do sistema nervoso central 


\begin{abstract}
BARBOSA, Amanda Matias. Clinical evaluation of somatosensory integrity in individuals with shoulder pain and a control group. 2019. 47 p. Dissertation (Master degree). Ribeirão Preto Medical School - University of São Paulo, Ribeirão Preto, 2019.
\end{abstract}

In musculoskeletal disorders, the most frequent complaint is pain, with shoulder disorders being extremely common, characterized by high incidence in the population, high cost and negative impact on functional aspects. Considered a worldwide problem, chronic pain affects about 60 million people, which corresponds to $10 \%$ of the world's population. The reorganization of the specific representation of the body region in the primary somatosensory cortex was identified as one of the changes in different populations of chronic pain. Thus, somatosensory integrity assessment tests such as left/right judgement task and two-point discrimination threshold are necessary to complement the clinical evaluation and for subsequent planning of a rehabilitation program for individuals with chronic pain. Objective: To compare the results of the as left/right judgement task and two-point discrimination threshold between individuals with chronic shoulder pain and no shoulder pain. It is believed that individuals with chronic shoulder pain have a higher response time and a lower accuracy in left/right judgement task as well as discriminate the perception of two points of tactile stimuli at a greater distance when compared to the control group. Materials and methods: The volunteers were submitted left/right judgement task by the Recognise Shoulder ${ }^{T M}$ application and the two-point discrimination threshold using the Mitutoyo® digital caliper. We also questioned the pain area, affectivity and functionality in order to characterize the sample. Fifty-two symptomatic cases were evaluated, with 37 women and 15 men with mean age of $54.1 \pm 9.25$ years, mean symptom time $40.56 \pm 39.93$ months and major right-side involvement. And asymptomatic individuals: 37 women and 13 men, with no complaints of shoulder pain, with a mean age of $44.98 \pm 11.75$ years, the majority being righthanded. Conclusion: We conclude that there is a difference in the left/right judgement task for the shoulder segment and the two-point discrimination threshold for a specific region of the shoulder between individuals with chronic shoulder pain and a control group.

Keywords: shoulder pain, chronic pain, pain perception, pain measurement, central nervous system sensitization. 


\section{LISTA DE ILUSTRAÇÕES}

Figura 1. Pontos de aplicação do teste de discriminação de dois pontos; Região anterior e superior (Ponto 1), Inserção distal do m. Deltóide (Ponto 2). Fonte: Laboratório de Análise da Postura e do Movimento Humano - LAPOMH............................................. 23

Figura 2. Ilustração do método staircase adaptado...................................................... 24 Figura 3: Fluxograma de participantes do grupo sintomático incluídos e avaliados na pesquisa. 


\section{LISTA DE TABELAS}

Tabela 1. Características sociodemográficas e clínicas da amostra de acordo com o grupo. 28

Tabela 2. Comparação entre os grupos sintomático e assintomático no teste de julgamento de lateralidade e no teste de discriminação de dois pontos 29 


\section{LISTA DE ABREVIATURAS E SIGLAS}

AN - Afetos Negativos

AP - Afetos Positivos

ARCO - Ambulatório de Reabilitação do Complexo do Ombro

CAAE - Certificado de Apresentação para Apreciação Ética

CSE - Centro Saúde Escola

DP - Desvio Padrão

END - Escala Númérica de Dor

EPM - Erro Padrão da Medida

FMRP - Faculdade de Medicina de Ribeirão Preto

IC - Intervalo de Confiança

JL - Julgamento de Lateralidade

PANAS - Positive and Negative affective Scale

PCS - Pain Catastrophizing Scale

SAS - Statistical Analysis System

S1 - Córtex Somatossensorial Primário

S2 - Córtex Somatossensorial Secundário

SMS - Secretaria Municipal de Saúde

SPADI - Índice de Incapacidade Relacionado a Dor no Ombro

TCLE - Termo de Consentimento Livre e Esclarecido

USP - Universidade de São Paulo 


\section{SUMÁRIO}

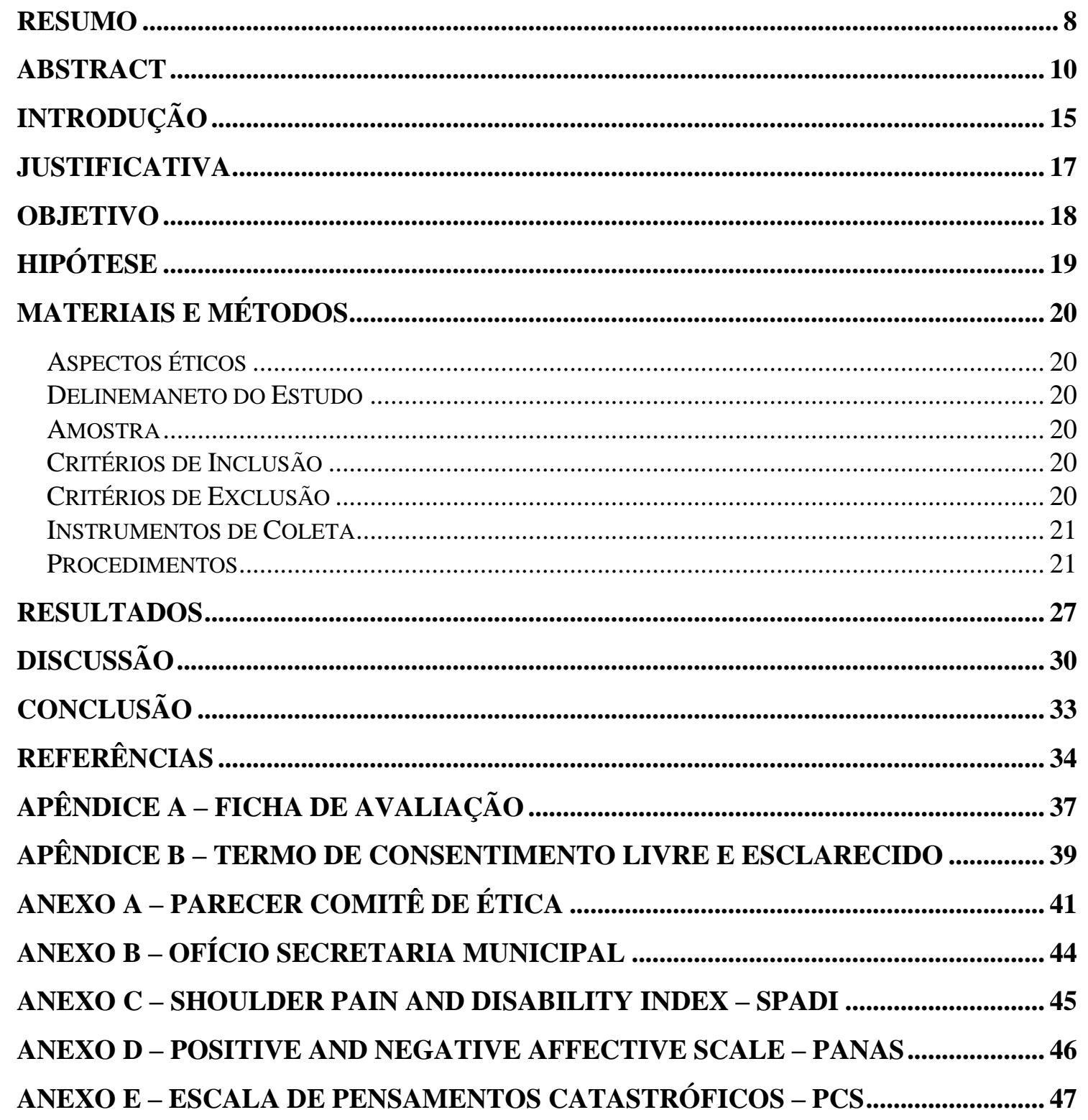




\section{INTRODUÇÃO}

Dentre as disfunções musculoesqueléticas, os distúrbios do ombro são extremamente comuns sendo a dor a queixa mais frequente (MARQUES et al, 2016). Além da alta incidência, alto custo e impacto negativo nos aspectos funcionais (TOSCANO et al, 2016), a dor no ombro costuma se apresentar de forma persistente ou recorrente, com 54\% de reaparecimento desse sintoma após 3 anos (LEWIS, 2009). Considerada um problema mundial, a dor crônica acomete cerca de 60 milhões de pessoas, o que corresponde a $10 \%$ de toda a população (MARQUES et al, 2016).

Os avanços dos métodos de neuroimagem permitiram investigar o processamento central cerebral da dor crônica dada a sua pobre relação com a lesão tecidual (JENSEN et al, 1994). A observação mais consistente na literatura é a de que exista uma diminuição da substância cinzenta principalmente no córtex pré-frontal em indivíduos com dor crônica, embora os resultados sejam variáveis e conflitantes a depender das diferentes metodologias, tamanho amostral, variabilidade clínica e demográfica e heterogeneidade nas condições de saúde subjacentes (YUAN et al 2017). Outras modificações observadas no cérebro envolvem a reorganização da representação específica da região do corpo no córtex somatossensorial primário (S1), (PLEGER et al 2006), menor área quando comparada a área contralateral que representa o segmento sadio (BRECKENRIDGE et al, 2017) e a possibilidade de existir uma sobreposição das áreas de representação do segmento como foi observado nos casos de amputação do membro e na dor lombar crônica (BOWERING et al, 2013).

Evidências sugerem que a organização somatotópica do segmento doloroso do cérebro de pessoas com dor crônica seja diferente de pessoas assintomáticas, seguindo um padrão único e específico para cada condição de dor (BALIK et al, 2014). A integridade do esquema corporal pode ser mensurada indiretamente pelo teste de julgamento de lateralidade (PARSONS E FOX, 1998). Para ser realizado o julgamento sobre qual parte do corpo pertence a imagem representada, é necessária uma rotação mental do corpo e uma comparação com o mapa interno, sugerindo que a redução na precisão reflete o esquema corporal afetado (BRAY E MOSELEY, 2011; MOSELEY E FLOR, 2012; PARSONS E FOX, 1998). Dessa forma a reorganização cortical do córtex somatossensorial também poderia contribuir para distúrbios motores (PLEGER et al 2006). 
Outra ferramenta clínica de avaliação indireta da representação somatotópica em S1 é o teste de discriminação de dois pontos (BOTNMARK; TUMILTY; MANI 2016). Inicialmente proposto como um teste de sensibilidade funcional ou teste de densidade de inervação e categorizado por Dellon como um teste de limiar de medida (MACKIN et al, 2002). Amplamente utilizado como avaliação de integridade da inervação no local testado após reparos cirúrgicos (LUNDBORG; ROSÉN, 2004). Existe grande variabilidade na literatura quanto ao protocolo a ser utilizado, a distância a ser determinada entre as ponteiras do instrumento de medida, o tipo de instrumento e a força inespecífica do examinador, que é uma variável não controlada (SKIRVEN et al, 2013).

Diversas condições clínicas de dor musculoesquelética indicam déficits no teste de julgamento de lateralidade, como maior tempo de resposta e menor porcentagem de acerto, comparados com indivíduos controle (BRECKENRIDGE et al, 2019; PELLETIER; HIGGINS; BOURBONNAIS, 2018). Casos de dor crônica como artrite, síndrome da dor complexa regional e dor lombar crônica trazem evidências de diminuição na acuidade tátil mas ainda é desconhecido se a anormalidade na acuidade tátil é uma característica da dor crônica, mesmo não havendo relato de aumento da acuidade tátil nesse condição (CATLEY et al, 2014).

Poucos estudos realizaram os testes de julgamento de lateralidade e discriminação de dois pontos especificamente para o segmento ombro a grande maioria deles avaliaram apenas indivíduos assintomáticos (BOTNMARK; TUMILTY; MANI, 2016; BRECKENRIDGE et al, 2015; BRECKENRIDGE et al, 2017; HEERKENS et al, 2018; KOO et al, 2016). Diante das evidências que demonstram a reorganização cortical mal adaptativa como uma característica da dor crônica, é reforçada a importância de uma investigação mais aprofundada do teste de julgamento de lateralidade e do teste de discriminação de dois pontos em indivíduos com dor crônica no ombro comparados a um grupo controle (BOTNMARK; TUMILTY; MANI, 2016). 


\section{JUSTIFICATIVA}

Acredita-se que a dor, especialmente a crônica provoque modificações anatômicas e funcionais no cérebro. Conforme observado na literatura, a dor crônica pode modificar áreas no cérebro relacionadas a representação do corpo. Essas modificações já foram relatadas em estudos sobre dor lombar (LUOMAJOKI e MOSELEY, 2011; ELSIG et al, 2014; BOWERING et al, 2013). As alterações da representação do corpo no cérebro vêm sendo estudadas a partir de métodos de neuroimagem, mas, esses métodos poder ser custosos e demandar tempo para a execução e para análise das imagens. O julgamento de lateralidade e a discriminação de dois pontos podem ser medidas mais simples e de fácil aplicação clínica que podem sugerir alterações da representação do corpo no cérebro (PLEGER et al, 2006). Os estudos que avaliaram as modificações da representação do corpo por meio de medidas clínicas em pessoas com dor crônica no ombro ainda são escassos na literatura. Desta maneira, este estudo pode contribuir com o conhecimento na área uma vez que as alterações do reconhecimento do segmento podem estar relacionadas a maior extensão da área de dor bem como para as alterações motoras (MOSELEY et al, 2012). 


\section{OBJETIVO}

Comparar os resultados dos testes de julgamento de lateralidade e de discriminação de dois pontos para o ombro entre indivíduos com dor crônica no ombro e sem dor no ombro. 


\section{HIPÓTESE}

Partimos da hipótese nula de que não existe diferença na discriminação de dois pontos e no julgamento de lateralidade entre pessoas com dor crônica no ombro e sem dor no ombro. A hipótese alternativa é que os indivíduos com dor crônica no ombro apresentem maior tempo de resposta e menor porcentagem de acerto na tarefa de julgamento da lateralidade bem como discriminem a percepção de dois pontos de estímulos táteis somente com a aplicação de distâncias maiores quando comparados ao grupo controle. 


\section{MATERIAIS E MÉTODOS}

\section{Aspectos Éticos}

Esse projeto de pesquisa foi submetido e aprovado pelo Comitê de Ética em Pesquisa do Centro Saúde Escola (CSE-Cuiabá) da Faculdade de Medicina de Ribeirão Preto da Universidade de São Paulo (FMRP-USP) de acordo com resolução 466/12 CNS/MS (CAAE 76637517.0.0000.5414) (Anexo A). Os voluntários foram informados sobre os objetivos e procedimentos da pesquisa. Foram orientados quanto aos seus direitos durante a realização da pesquisa, incluindo a garantia de total anonimato, sua liberdade de participação e possível desistência em qualquer período da pesquisa, sem qualquer punição, sendo assim, assinaram o Termo de Consentimento Livre e Esclarecido (TCLE) (Apêndice A).

\subsection{Participantes}

As pessoas com dor crônica no ombro foram recrutadas a partir da análise das guias de encaminhando para atendimento de fisioterapia em um serviço público de saúde. Os voluntários do grupo controle foram selecionados apenas a partir da divulgação do projeto pelas redes sociais, cartazes e folhetos informativos. Os indivíduos foram submetidos a uma entrevista breve para se avaliar os critérios de elegibilidade para o estudo. Aqueles que aceitaram participar do estudo foram convidados a comparecer para avaliação no serviço público de atendimento fisioterapêutico ou no laboratório de pesquisa da universidade.

Para o grupo de participantes com dor no ombro foram considerados como critérios de elegibilidade: (1) idade superior a 30 anos, (2) queixa principal de dor ombro, (3) ausência de dor irradiada para os membros superiores, (4) ausência de sintomas neurológicos como parestesia no membro superior, (5) dor por mais de 12 semanas e (6) dor de origem traumática ou após cirurgia do ombro. Não foram considerados elegíveis para o estudo aquelas pessoas que relataram diagnósticos clínicos que pudessem ser sugestivos de sensibilização central como fibromialgia, síndrome de dor complexa regional, enxaqueca ou cefaleia tensional, síndrome de fadiga crônica, disfunção temporomandibular, síndrome do intestino irritável, lesão em chicote cervical, síndrome das pernas inquietas, transtornos de ansiedade, síndrome de estresse pós traumático, sensibilidade química múltipla e depressão. Os voluntários que apresentavam déficits 
cognitivos impedindo-os de responder aos questionários, voluntários que estavam em tratamento fisioterapêutico no momento ou nos últimos seis meses, aqueles que apresentavam dores no ombro ou em outras partes do corpo de origem traumática como aquelas resultantes de pós-fratura ou pós-luxação nos últimos dois anos também não foram considerados elegíveis.

Para o grupo de participantes assintomáticos foram considerados os seguintes critérios de elegibilidade: (1) ter mais de 30 anos, (2) não ter nenhuma queixa de dor no ombro. Não foram considerados elegíveis para o grupo assintomático os voluntários que relataram queixa de dor nos membros superiores, cintura escapular ou coluna cervical no momento da avaliação ou aqueles com história de dor no ombro nos últimos dois anos (que tivesse sido suficiente para restringir o trabalho ou lazer por mais de dois dias), aqueles com alguma doença neurológica capaz de acarretar algum déficit sensoriomotor ou cognitivo, pessoas com uso de alguma substância capaz de afetar a sensibilidade ou a atenção, indivíduos com distúrbios cognitivos e gravidez. Esses participantes foram pareados pela idade com o grupo sintomático.

\subsection{Instrumentos de coleta}

A coleta dos dados foi composta da avaliação sociodemográfica, do teste de julgamento de lateralidade, do teste de discriminação de dois pontos, da avaliação da dor e incapacidade e da predominância dos afetos.

\subsubsection{Avaliação dos dados sociodemográficos}

Os participantes sintomáticos foram avaliados de acordo com o roteiro de entrevista de triagem, anamnese e exame físico do Ambulatório de Reabilitação do Complexo do Ombro - ARCO. Esse roteiro permitiu registrar informações pessoais e informações biopsicossociais úteis para caracterização da amostra do estudo (APENDICE B).

\subsubsection{Teste de Julgamento de lateralidade (TJL)}

Para o teste de julgamento de lateralidade do ombro foi utilizado o aplicativo Recognise Shoulder $^{T M}$ (Neuro Orthopaedic Instituteb- NoiGroup, Adelaide AS, AUS) para smartphones e tablets. Este teste apresenta alta confiabilidade (BRECKENRIDGE et al 2017; WILLIAMS et al, 2019) e se baseia na apresentação de imagens de segmentos corporais em diferentes posições. O teste foi realizado utilizando um tablet de 9,7 
polegadas (Samsung® Eletronics, Galaxy Tab A, Seul, ROK). Para a apresentação, foi selecionada a opção Vanilla que apresenta imagens do segmento ombro em diferentes posições, em um fundo neutro. A apresentação das imagens do ombro aconteceu de maneira aleatória definida pelo próprio aplicativo e cada foto foi apresentada por cinco segundos. O voluntário foi orientado a selecionar na tela do tablet (touchscreen) a palavra direita ou esquerda, conforme julgamento das imagens. No aplicativo as palavras "direita" e "esquerda" estão em língua inglesa e por isso foi colocado um recorte de aviso com as palavras "direita" e "esquerda" na língua portuguesa definindo o lado a qual correspondiam.

O procedimento iniciou com familiarização da tarefa com a visualização de 30 imagens do segmento pé. Para a familiarização foi utilizado o aplicativo Recognise Foot ${ }^{T M}$, também na opção Vanilla, com diversas imagens dos pés, apresentadas por 5 segundos para cada imagem. Após a familiarização foi apresentada uma sequência de 30 imagens do ombro, no tempo de 5 segundos cada, por três repetições e o participante foi orientado a avaliar a imagem apresentada e responder por meio do toque na tela do Tablet com a maior velocidade e certeza de resposta possível. O intervalo entre a bateria dos testes foi de um minuto (BOTNMARK; TUMILTY; MANI, 2016). Os desfechos considerados foram o tempo médio de resposta em segundos e a porcentagem de acerto na tarefa de julgamento da lateralidade do ombro.

\subsubsection{Teste de Discriminação de Dois Pontos}

Para o teste de discriminação de dois pontos, os participantes foram posicionados confortavelmente em uma cadeira com o tronco e os membros superiores apoiados sobre as próprias pernas. $\mathrm{O}$ teste de discriminação de dois pontos foi realizado com o paquímetro digital (Mitutoyo®, Suzano, SP, Brasil). Este teste apresenta alta confiabilidade (ADAMCZYK et al, 2016; CATLEY et al, 2013). A sensibilidade discriminativa dos ombros foi avaliada em dois locais: 1-) representado as raízes nervosas de C3 e C4, na área de inervação sensorial do nervo supraclavicular, uma medida foi realizada no aspecto ântero-superior do ombro, levando-se em consideração cinco centímetros a partir do acrômio em direção cranial e, 2) representando as raízes nervosas de C5 e C6, na região de abrangência do nervo cutâneo lateral superior do braço do nervo axilar, no aspecto lateral do ombro, levando-se em consideração a inserção distal do músculo deltoide (Figura 1), totalizando assim, duas áreas de inferência do esquema 
corporal relativo ao ombro (BAYAM et al, 2011; DAVEY; NOWICKY; ZAMAN, 2000). O teste foi feito com o paquímetro no plano transverso.

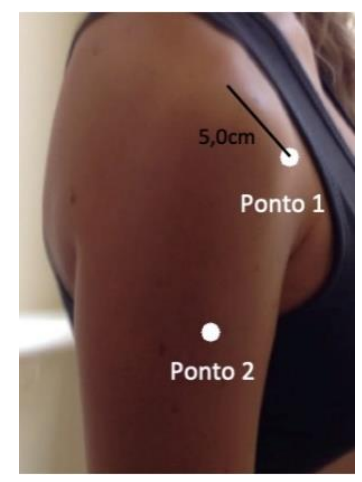

Figura 1. Pontos de aplicação do teste de discriminação de dois pontos. Região anterior= ponto 1, marcado $5 \mathrm{~cm}$ abaixo do acrômio. Região lateral= ponto 2 , sobre a tuberosidade deltoidea.

A acuidade tátil foi avaliada em uma única sessão. Inicialmente ocorreu uma familiarização do teste na região do antebraço para que o participante diferenciasse a sensação pertencente ao toque de um ou dois pontos. Na realização do teste, o participante permaneceu com os olhos vendados e durante a aplicação do paquímetro ele foi orientado a responder a sua percepção de acordo com três opções de resposta: "um ponto", "dois pontos" ou "não sei” (BOTNMARK; TUMILTY; MANI, 2016).

O teste teve início com o paquímetro ajustado a uma distância de $20,0 \mathrm{~mm}$ entre as suas duas ponteiras. A distância foi gradualmente aumentada de 2,0 em 2,0mm até que o participante relatasse verbalmente a percepção de que dois pontos foram tocados. Posteriormente, a sequência descendente foi aplicada até a percepção de um ponto. Esse procedimento foi repetido duas vezes de modo que o escore do teste de discriminação de dois pontos foi baseado na média de quatro distâncias encontradas: duas ascendentes e duas descendentes. Esse método também incluiu dois momentos definidos como "ponto nulo", ou seja, o toque de apenas uma das ponteiras do paquímetro a fim de minimizar a chance de viés de resposta (Figura 2) (KLEIN, 2001). Valores menores das médias das quatro distâncias indicam maior acuidade tátil. O protocolo de avaliação da discriminação de dois pontos foi adaptado para o ombro de acordo com um estudo prévio feito com indivíduos com diagnóstico de dor lombar seguindo o método staircase adaptado (ADAMCZYK et al 2017). 
A ordem de aplicação do estímulo tátil quanto ao ombro direito ou esquerdo, região anterior ou lateral e o momento de aplicação dos dois "pontos nulos" foi definida mediante randomização prévia. O valor médio das quatro respostas foi considerado como limiar de discriminação de dois pontos. A duração do teste variou de acordo com a capacidade dos voluntários em discriminar dois pontos.

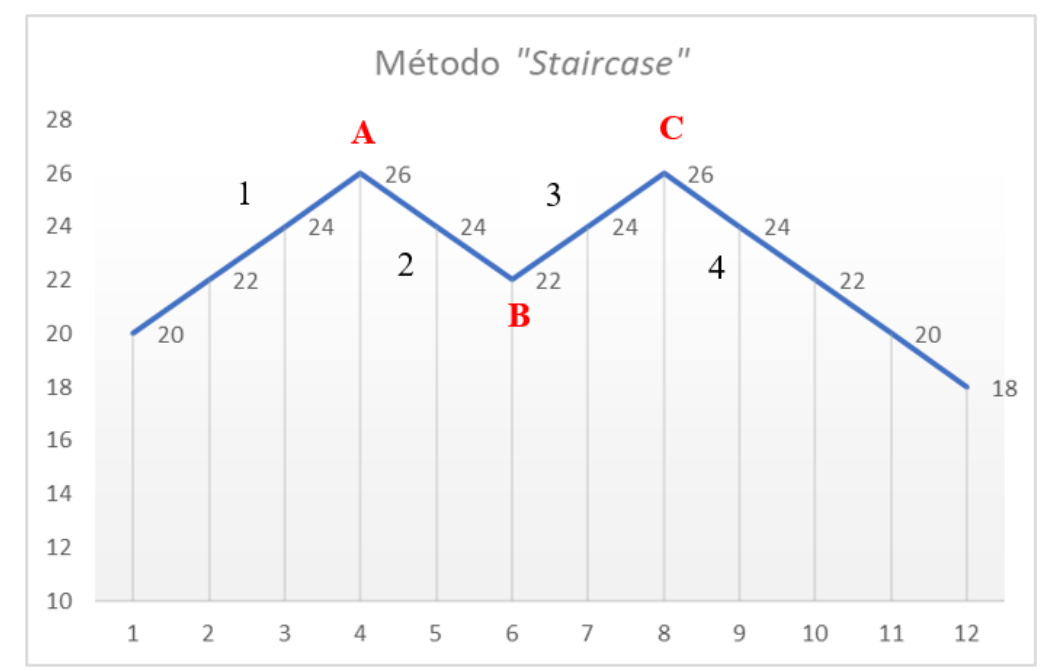

Figura 2. Ilustração do método staircase. Para todos os participantes o teste começou a partir de $20 \mathrm{~mm}$, seguido de um aumento da distância entre as ponteiras do paquímetro. Duas das três letras A, B ou C foram sorteadas pelo voluntário e indicam os "pontosnulos". Necessariamente, após a aplicação do ponto-nulo houve mudança no direcionamento da distância das ponteiras do paquímetro (aplicação ascendente ou descendente). Os números 1 e 3 referem-se ao momento ascendente, ou seja, aumento da distância das ponteiras do paquímetro a fim de quantificar a distância que o indivíduo relatava perceber dois pontos. Já os números 2 e 4 referem-se ao momento descendente, ou seja, diminuição da distância das ponteiras do paquímetro a fim de identificar a distância que o indivíduo referia sentir apenas um ponto.

\subsection{Dor e Incapacidade}

O questionário Shoulder Pain and Disability Index (SPADI), foi aplicado no grupo sintomático a fim de avaliar a dor e a incapacidade associadas as disfunções no ombro. Foi utilizada a versão adaptada transculturalmente para o Brasil apresentando excelente confiabilidade (ICC 0,90) e consistência interna de medida (Alpha de Cronbach 0,89) (MARTINS et al, 2010). A pontuação varia de 0 a $100 \%$, sendo que quanto maior a pontuação, pior a condição de disfunção do ombro. Ainda não existem valores de corte para os resultados obtidos pelo SPADI nas condições do ombro (MARTINS et al, 2010). 


\subsection{Mensuração da área de dor}

Para o grupo de indivíduos com dor crônica no ombro, foi realizada a mensuração da área dolorosa por meio do aplicativo de desenho Sketchbook instalado em um tablet de 9,7 polegadas (Samsung® Eletronics, Galaxy Tab A, Seul, ROK). O indivíduo foi instruído a preencher a área de dor em um mapa representativo da silhueta do corpo humano nas visões anterior e posterior utilizando uma caneta para tablet. Em seguida as imagens eram salvas e importadas para o aplicativo Sketchbook e posteriormente analisadas utilizando o software Body Chart Analyser V1.6, de excelente confiabilidade (CASEIRO et al, 2019), a fim de quantificar a área dolorosa. A intensidade da dor foi mensurada por meio da Escala Visual Numérica considerando 0 a ausência total de dor e 10 a intensidade de dor máxima suportada pelo indivíduo.

\subsection{Aspectos afetivos}

A Escala de Afetos Positivo e Negativo (PANAS) foi respondida pelo grupo sintomático e assintomático. A escala tem evidências psicométricas de validade estrutural e consistência interna, e é composta por 20 palavras sendo 10 relacionadas a aspectos positivos e 10 palavras que se referem a aspectos negativos (CARVALHO et al, 2013). Cada uma das palavras descreve o modo do indivíduo pensar sobre si mesmo e é avaliada pelos participantes em uma escala Likert de cinco pontos relacionado a frequência desse sentimento (CARVALHO et al, 2013). O espectro temporal considerado foi o último mês, sendo que a escala já foi traduzida para a língua original do país (PEREIRA; CALVANO; CUNHA, 1992).

O grupo com dor crônica no ombro também foi avaliado por meio da Escala de Pensamento Catastrófico sobre a Dor (B-PCS) já adaptada e validada para o Brasil. Os indivíduos indicavam o grau do pensamento ou sentimento em uma escala de 0 a 4 em 13 declarações ditas pelo examinador, levando em consideração o momento em que estava com dor no ombro acometido. Maiores valores indicam maior catastrofização sendo que 30 pontos é considerado o ponto de corte. Além disso as declarações do questionário englobam os domínios de magnificação, ruminação e desesperança relacionado a dor (SEHN et al 2012).

\subsection{Análise estatística}

O software estatístico utilizado foi o R Core Team (2016). R: A language and environment for statistical computing, R Foundation for Statistical Computing, Vienna, 
Austria. E o SAS Statistical Software (version 9.3; SAS Institute, Inc. Cary, NC). Os dados são apresentados utilizando a análise de frequência relativa e absoluta e as análises de tendência central (média) e dispersão (desvio padrão, mínimo e máximo) das variáveis contínuas. Para a comparação das variáveis tempo de resposta e porcentagem de acerto no teste de julgamento da lateralidade no segmento ombro e para comparação do teste de discriminação de dois pontos entre os indivíduos sintomáticos e assintomáticos foi utilizado um modelo de regressão linear com efeitos mistos a partir da média das respostas. Para esta comparação entre os grupos foi considerado a média das respostas do ombro sintomático e para o grupo assintomático considerou-se o ombro dominante. Os dados são apresentados pela diferença das médias e o intervalo de confiança. Considerouse um nível de significância de $95 \%$. 


\section{RESULTADOS}

\subsection{Característica da amostra}

O fluxograma do processo de seleção indivíduos com dor crônica no ombro incluídos e avaliados na pesquisa está disposto na Figura 3.

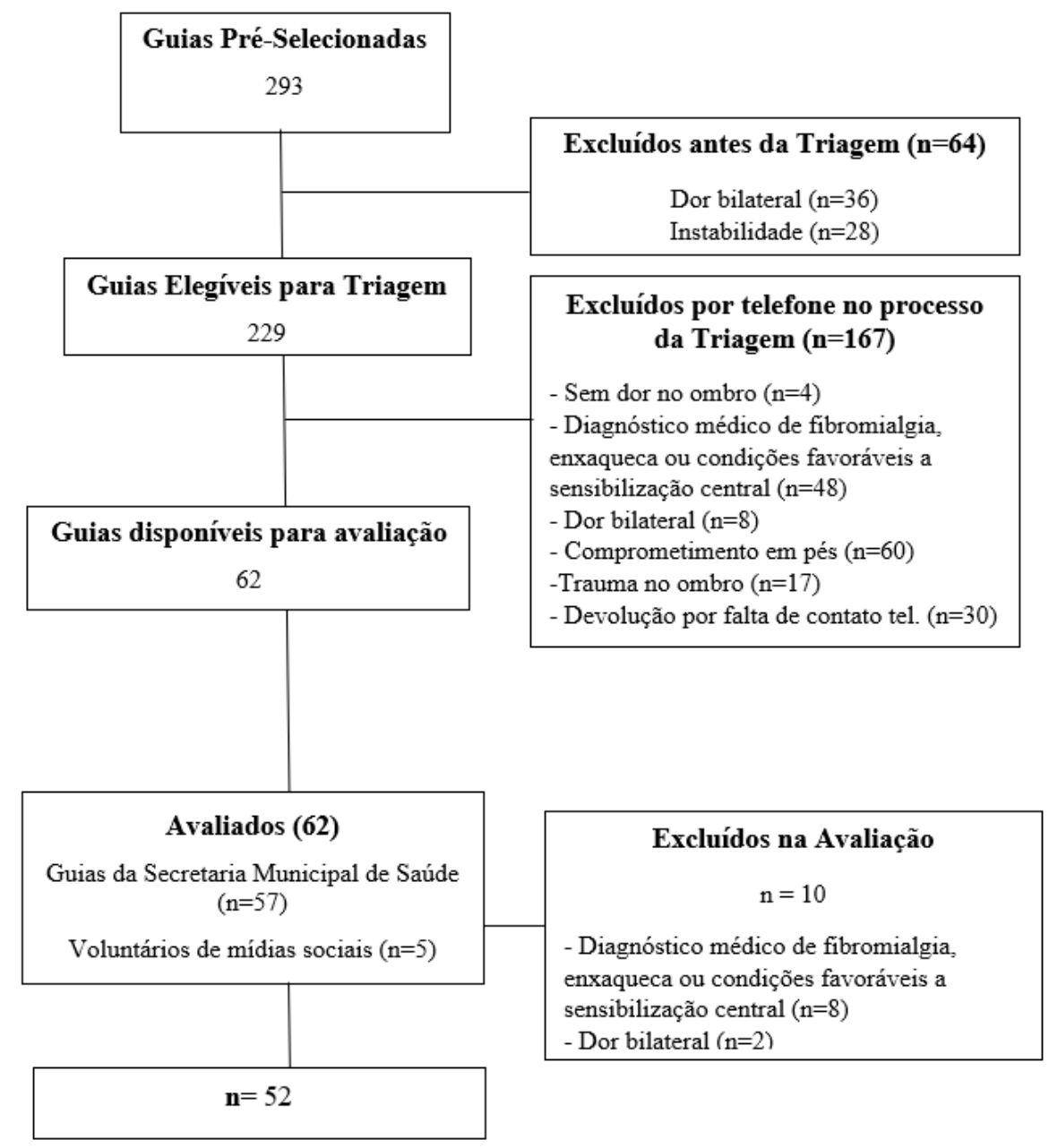

Figura 1: Fluxograma de participantes do grupo sintomático incluídos e avaliados na pesquisa.

O grupo de pessoas com dor no ombro incluiu 37 mulheres e 15 homens com dor crônica unilateral não traumática com média de idade de 54,1 (DP=9,25) anos, tempo médio de sintoma 40,56 ( $\mathrm{DP}=39,93)$ meses, intensidade de dor segundo Escala Visual Analógica de 2,2 ( $\mathrm{DP}=3,0)$, porcentagem de área dolorosa de 3,83 $(\mathrm{DP}=3,86)$ e maior acometimento do lado direito. A média da pontuação total do SPADI foi de 48,56 ( $\mathrm{DP}=25,98)$, do PANAS afeto positivo $35,8(\mathrm{DP}=8,51)$ e PANAS afeto negativo 23,48 
$(\mathrm{DP}=8,76)$ e de catastrofização 23,88 ( $\mathrm{DP}=11,91)$. O grupo assintomático continha 37 mulheres e 13 homens, com média de idade de 44,98 ( $\mathrm{DP}=11,75)$ anos, sendo a grande maioria destros. A média da pontuação do PANAS afeto positivo foi $36,54(\mathrm{DP}=7,55)$ e PANAS afeto negativo 21,7 (DP=7,21). A Tabela 1 apresenta os dados de caracterização do grupo sintomático e assintomático

Tabela 1: Características sociodemográficas e clínicas da amostra de acordo com o grupo.

\begin{tabular}{lcc}
\hline \multicolumn{1}{c}{ Variável } & $\begin{array}{c}\text { Grupo } \\
\text { Sintomático }\end{array}$ & $\begin{array}{c}\text { Grupo } \\
\text { Assintomático }\end{array}$ \\
\hline Sexo, n (\%) & $71(\%)$ & $74(\%)$ \\
$\quad$ Feminino & $29(\%)$ & $26(\%)$ \\
$\quad$ Masculino & & \\
Lado Acometido, n (\%) & $77(\%)$ & \\
$\quad$ Direito & $23(\%)$ & \\
$\quad$ Esquerdo & $54,1(9,25)$ & $44,98(11,75)$ \\
Idade, média (DP) & $40,56(39,93)$ & \\
Tempo de Sintoma, média (DP) (meses) & $2,2(3,04)$ & \\
Intensidade de dor, média (DP) (0-10) & $3,83(3,86)$ & \\
Área de dor, média (DP) (0-100\%) & & \\
SPADI, média (DP) (0-100\%) & $48,56(25,98)$ & \\
$\quad$ Total & & \\
PANAS, média (DP) (20-100) & $35,80(8,51)$ & \\
$\quad$ Positivo & $23,48(8,76)$ & \\
$\quad$ Negativo & $23,88(11,91)$ & \\
PCS, média (DP) (0-52) & & \\
\hline
\end{tabular}

\subsection{Julgamento de lateralidade e discriminação de dois pontos}

A comparação dos resultados do julgamento de lateralidade demonstrou haver diferença estaticamente significativa para a média do tempo de resposta do ombro sintomático (média=1,54; $\mathrm{DP}=0,42$ ) com o ombro dominante do grupo assintomático (média=1,37; DP=0,37) $[\mathrm{IC}(95 \%)=0,02$ a 0,$31 ; \mathrm{p}=0,025)$. Em relação a porcentagem de acertos, o grupo sintomático apresentou valor médio de acertos menor quando comparado com o grupo controle. No entanto, essa diferença não foi estatisticamente significativa. Para o teste de discriminação de dois pontos, a comparação dos resultados entre os grupos sintomático e assintomático demonstra haver diferença estatisticamente significativa $(\mathrm{p}=0,0125)$ somente para a região lateral do ombro. Os resultados para o julgamento da lateralidade e para a discriminação de dois pontos estão apresentados na Tabela 2. 
Tabela 2: Comparação entre os grupos sintomático e assintomático considerando o tempo de resposta e a porcentagem de acerto no teste de julgamento de lateralidade e os valores médios para discriminação de dois pontos.

\begin{tabular}{|c|c|c|c|}
\hline Variável & $\begin{array}{c}\text { Grupo } \\
\text { Sintomático } \\
\text { média (DP) } \\
\end{array}$ & $\begin{array}{c}\text { Grupo } \\
\text { Assintomático } \\
\text { média (DP) }\end{array}$ & IC $(95 \%)$ \\
\hline \multicolumn{4}{|c|}{ Julgamento de Lateralidade } \\
\hline \multicolumn{4}{|c|}{ Tempo de resposta } \\
\hline $\begin{array}{l}\text { Ombro sintomático } \\
\text { vs ombro dominante }\end{array}$ & $1,54(0,42)$ & $1,37(0,37)$ & 0,02 a $0,31 *$ \\
\hline \multicolumn{4}{|l|}{ Porcentagem de acerto } \\
\hline $\begin{array}{l}\text { Ombro sintomático } \\
\text { vs ombro dominante }\end{array}$ & $90,64(9,87)$ & $91,21(12,65)$ & $-4,91$ a 3,78 \\
\hline \multicolumn{4}{|c|}{ Discriminação de dois pontos } \\
\hline \multicolumn{4}{|c|}{$\begin{array}{l}\text { Ombro sintomático vs ombro } \\
\text { dominante }\end{array}$} \\
\hline Região anterior & $28,08(11,04)$ & $25,38(8,80)$ & $-0,35$ a 5,76 \\
\hline Região lateral & $27,86(9,92)$ & $23,96(8,37)$ & 0,84 a $6,95 *$ \\
\hline
\end{tabular}




\section{DISCUSSÃO}

Este estudo teve como objetivo comparar o tempo de resposta e o percentual de acertos no teste de julgamento de lateralidade e capacidade de discriminação de dois pontos considerando o ombro sintomático de pessoas com dor no ombro com característica predominantemente nociceptiva quando comparadas a um grupo de pessoas sem dor no ombro. Os resultados obtidos para o ombro sintomático mostram que as pessoas com dor no ombro apresentaram, tempo médio de resposta maior que o que o grupo assintomático e maior distância para o reconhecimento de dois pontos na face lateral do braço. Os resultados desse estudo apoiam a hipótese de que o grupo com dor crônica no ombro tem pior desempenho no tempo de resposta para o julgamento de lateralidade e só conseguem discriminar a percepção tátil de dois pontos sobre a pele da região deltoide à uma distância mínima maior que a do grupo controle.

Nesse estudo, foram incluídos indivíduos com dor crônica unilateral no ombro com predomínio de característica nociceptiva, com média de idade de 54 anos, o tempo médio de resposta para o julgamento de lateralidade foi de 1,37 segundos com taxa de acerto de $91.2 \%$. Este é o primeiro estudo que compara o tempo e a porcentagem de acerto no teste de julgamento de lateralidade incluindo pessoas com dor no ombro com uma classificação neurofisiológica da dor específica, ou seja, não foram elegíveis aqueles pacientes com dor neuropática ou nociplástica comparando esses resultados com controles saudáveis. Os valores de tempo de resposta obtidos no teste de julgamento de lateralidade do presente estudo são comparáveis aos valores normativos para voluntários assintomáticos encontrados na literatura que vão de 1.3 a 1.7 segundos (BOTNMARK; TUMILTY; MANI, 2016; BRECKENRIDGE et al, 2015; BRECKENRIDGE et al, 2017; BRECKENRIDGE et al, 2019; HEERKENS et al, 2018). No entanto a porcentagem de acerto é menor que as anteriormente relatadas, que vão de 93.8 a $94 \%$ na tarefa de julgar imagens de ombros (BOTNMARK; TUMILTY; MANI, 2016; BRECKENRIDGE et al, 2015; BRECKENRIDGE et al, 2017; BRECKENRIDGE et al, 2019; HEERKENS et al, 2018). Embora no presente estudo, os sujeitos com dor no ombro apresentem um tempo de resposta maior para fazer o julgamento de lateralidade quando comparados ao grupo controle, a porcentagem de acertos não foi diferente entre os grupos. Isso nos leva a concluir que ainda não há como discriminar sujeitos com dor crônica unilateral no ombro de indivíduos sem a condição usando o teste de julgamento de lateralidade e mais estudos são necessários. A literatura demonstra não haver efeito da dominância sobre tempo de 
resposta e a porcentagem de acerto no teste de julgamento da lateralidade (BRECKENRIDGE et al, 2017), por isso lados direito e esquerdo não foram considerados separadamente no nosso estudo.

De fato, em uma revisão sistemática com metanálise recente, os autores agruparam os estudos com pessoas dor crônica no membro superior $(n=134)$ comparando com um grupo controle saudável $(n=84)$. Os resultados demonstraram que pessoas com dor crônica no membro superior são menos precisas na discriminação entre imagens da esquerda e da direita do que pessoas saudáveis. Entretanto, os estudos incluídos apresentaram heterogeneidade moderada $\left(\mathrm{I}^{2}=56 \%, \mathrm{p}=0,03\right)$, potencialmente em virtude ao agrupamento desses resultados (BRECKENRIDGE et al, 2019).

No presente estudo, a média da distância mínima para discriminar a percepção tátil de dois pontos foi de $28.08 \mathrm{~mm}$ para a região anterior e $27.86 \mathrm{~mm}$ para a região da tuberosidade deltoidea nos indivíduos com dor crônica. Os assintomáticos, em média, discriminaram dois pontos a distância mínima de $25.38 \mathrm{~mm}$ para a região anterior e 23.96 mm para a região da tuberosidade deltoidea. Embora a distância mínima para a discriminação de dois pontos seja sempre maior para o grupo com dor no ombro, apenas sobre a região próxima a tuberosidade deltoidea ela foi significativamente diferente do grupo controle. Estudos anteriores (BOTNMARK; TUMILTY; MANI, 2016; CATLEY et al, 2014; HEERKENS et al, 2018; KOO et al 2016; MANCINI et al, 2014; NOLAN, 1982) avaliaram sujeitos assintomáticos e jovens, com idades entre 22 e 25 anos e encontraram valores variando de $18^{20}$ a $44.2^{13} \mathrm{~mm}$ para discriminar dois pontos sobre a região anterior do ombro, de $30 \mathrm{~mm}$ na região supero-posterior ${ }^{13}$ e de 44,8 sobre a região lateral $^{13}$. Essa variação entre os valores mínimos para discriminação de dois pontos na região do ombro deve ser interpretada considerando as características das amostras avaliadas com relação a idade e presença de sintomas ou não ${ }^{14,16,17}$, aos diferentes métodos e protocolos propostos pelos autores para obter o valor referente a percepção do sujeito ( BOTNMARK; TUMILTY; MANI, 2016; CATLEY et al, 2014; HEERKENS et al, 2018; KOO et al 2016) e ao fato do teste de discriminação de dois pontos é avaliador dependente em virtude do controle da pressão aplicada pelo examinador (LUNDBORG; ROSÉN, 2004). Na prática clínica, se o examinador optar por usar o protocolo staircase conforme aplicado no presente estudo, recomendamos que o faça apenas sobre a região lateral próxima a tuberosidade deltoide, onde os valores discriminaram os grupos com dor e controle. 
As medidas indiretas da representação somatotópica em S1 usadas nesse estudo foram úteis para diferenciar os grupos de dor crônica unilateral de origem atraumática no ombro e controles. No entanto, são necessários mais estudos que avaliem a condição específica de dor musculoesquelética no ombro, incluindo amostras maiores, com diferentes características clínicas uma vez que mudanças na reorganização funcional dos sistemas somatossensorial e motor aumentam com a cronicidade e estão associadas com a intensidade de dor (FLOR, 2003).

\section{LIMITAÇÕES DO ESTUDO}

Dois examinadores realizaram os testes de discriminação de dois pontos e de julgamento de lateralidade conforme conveniência, tanto para grupo sintomático quanto assintomático. 


\section{CONCLUSÃO}

Esse estudo demonstra que existe diferença para o tempo de resposta do teste de julgamento de lateralidade para o segmento ombro e no teste de discriminação de dois pontos para uma região específica do ombro entre indivíduos com dor crônica no ombro e um grupo controle. Além disso, os resultados obtidos podem ser utilizados como valores de referência para uma amostra dolorosa e de indivíduos sem sintomas de dor no ombro. 


\section{REFERÊNCIAS}

1. Adamczyk et al. Tactile acuity (dys)function in acute nociceptive low back pain: a double-blind experiment. Pain, v.0, n.0, 2017.

2. BALIKI et al. Functional Reorganization of the Default Mode Network across Chronic Pain Conditions. Plos One, v.9, n.9, p.1-13, 2014.

3. BAYAM et al. Pain mapping for common shoulder disorders. American Journal of Orthopedics, v.40, n.7, p.353-358, 2011.

4. BRAY, H; MOSELEY, G.L. Disrupted working body schema of the trunk in people with back pain. The American Journal of Sports Medicine, v. 45, n. 3, p. 168-173, 2011.

5. BRECKENRIDGE, J. D. et al. Shoulder left/right judgement task: development and establishment of a normative dataset. WCPT Congress, v. 101, n.1, p. 169, 2015.

6. BRECKENRIDGE, J. D. et al. The development of a shoulder specific left/right judgement task: validity \& reliability. Musculoskeletal Science and Practice, v. 28, n.11, p. 39-45, 2017.

7. BRECKENRIDGE, J. D. et al. Do People With Chronic Musculoskeletal Pain Have Impaired Motor Imagery? A Meta-analytical Systematic Review of the Left/Right Judgment Task. The Journal of Pain, v. 20, n.2, p. 119-132, 2019.

8. BOTNMARK, I.; TUMILTY, S; MANI, R. Tactile acuity, body schema integrity and physical performance of the shoulder: a cross-sectional study. Manual Therapy, v. 23, n.11, p. 09-16, 2016.

9. BOWERING, K. J. et al. The effects of graded motor imagery and its components on chronic pain: a systematic review and meta-analysis. The Journal of Pain, v. 14, n. 01, p. 03-13, 2013.

10. CARVALHO et al. Structural validity and reliability of the Positive and Negative Affect Schedule (PANAS): Evidence from a large Brazilian community sample. Revista Brasileira de Psiquiatria, v.35, p.169-172, 2013.

11. CASEIRO M. et al. From Paper to Digitalized Body Map: A Reliability Study of the Pain Area. Pain Practice, 2019.

12. CATLEY et al. Assessing tactile acuity in rheumatology and musculoskeletal medicine - how reliable are two-point discrimination tests at the neck, hand, back and foot? Rheumatology, v.52, p.1454-1461, 2013. 
13. CATLEY et al. Is Tactile Acuity Altered in People With Chronic Pain? A Systematic Review and Meta-analysis. The Journal of Pain, v.15, n.10, p.985-1000, 2014.

14. DAVEY, N.J.; NOWICKY, A.V.; ZAMAN, R. Somatotopy of perceptual threshold to cutaneous electrical stimulation in man. Experimental Physiology, v.86, n.1, p.127-130, 2000.

15. ELSIG, S. et al. Sensorimotor tests, such as movement control and laterality judgment accuracy, in persons with recurrent neck pain and controls. A case-control study. Manual therapy, n.11, p. 01-07, 2014.

16. FLOR, H. Cortical reorganisation and chronic pain: implications for rehabilitation. Journal of Rehabilitation Medicine, v.41, p.66-72, 2003.

17. HEERKENS, J.H. et al. Motor imagery performance and tactile acuity in patients with complaints of arms, neck and shoulder. Pain Management, v.8, n.4, p.277-286, 2018.

18. JENSEN et al. Magnetic Resonance Imaging of the lumbar spine in people without back pain. The New England Journal of Medicine, v.331, n.2, p.69-73, 1994.

19. KLEIN, S.A. Measuring, estimating, and understanding the psychometric function: A commentary. Perception\& Psychophysics, v.63, n.8, p.1421-1455, 2001.

20. KOO et al. Two-point discrimination of the upper extremities of healthy Koreans in their 20's. The Journal of Physical Therapy Science, v.28, n.3, p.870-874, 2016.

21. LEWIS, J S. Rotator cuff tendinopathy/subacromial impingement syndrome: is it time for a new method of assessment? The American Journal of Sports Medicine, v. 43, n.11, p. 259-264,2009.

22. LUNDBORG; G.; ROSÉN; B. The two-point discrimination test - time for a reappraisal? The Journal of Hand Surgery, v.29, n.5, p.418-422, 2004.

23. LUOMAJOKI, H; MOSELEY, G L. Tactile acuity and lumbopelvic motor control in patients with back pain and healthy controls. The American Journal of Sports Medicine, v. 45, n.11, p. 437-440, 2011.

24. MACKIN et al. Rehabilitation of the Hand and Upper Extremity, Fifth Edition, Volume 1, 2002.

25. MANCINI et al. Whole-Body Mapping of Spatial Acuity for Pain and Touch. ANNALS of Neurology, v.0, n.0, p.1-9, 2014.

26. MARQUES, E. S. et al. Evaluation of physiologic pain knowledge by physiotherapy students. Revista de Dor, v. 17, n. 01, p. 29-33,2016. 
27. MARTINS et al. Versão brasileira do Shoulder Pain and Disability Index: tradução, adaptação cultural e confiabilidade*. Revista Brasileira de Fisioterapia, v.14, n.6, p.527-536, 2010.

28. MOSELEY, G.L. et al. The Graded Motor Imagery Handbook, primeira Edição, Austrália, 2012.

29. MOSELEY, G. L.; FLOR, H. Targeting cortical representations in the treatment of chronic pain: a review. Neurorehabilitation and Neural Repair, v. 26, n. 06, p. 646$652,2012$.

30. NOLAN; M.F. Two-Point Discrimination Assessment in the Upper Limb in Young Adult Men and Women. Physical Therapy, v.62, n.7, p.965-969, 1982.

31. PARSONS, L. M.; FOX, P. T. The neural basis of implicit movements used in recognising hand shape. Cognitive Neuropsychology, v. 15, p. 583-615, 1998.

32. PELLETIER, R.; HIGGINS, J.; BOURBONNAIS, D. Laterality recognition of images, motor performance, and aspects related to pain in participants with and without wrist/hand disorders: An observational cross-sectional study. Musculoskeletal Science and Practice, v.35, p.18-24, 2018.

33. PEREIRA, C.A.A.; CALVANO, N.; CUNHA, V. C. Estados de ânimo e bem-estar subjetivo: Um estudo com LEP, PANAS-S e BES [Mood states and well-being: A LEP, PANAS and BES study]. Paper presented at the XXII Reunião Anual de Psicologia da Sociedade Brasileira de Psicologia. Ribeirão Preto, Brazil, 1992.

34. PLEGER et al. Patterns of cortical reorganization parallel impaired tactile discrimation and pain intensity in complex regional pain syndrome. Neuroimage, v.32, p.503-510, 2006.

35. SEHN et al. Cross-Cultural Adaptation and Validation of the Brazilian Portuguese Version of the Pain Catastrophizing Scale. Pain Medicine, n.12, p.1425-1435, 2012.

36. SKIRVEN et al. Rehabilitation of the Hand and Upper Extremity, Sixth Edition, Volume 2, 2013.

37. TOSCANO, J. J. de O. et al. Pain prevalence on public servants: association with sedentary behavior and physical leisure activity. Revista de dor, v. 17, n. 02, p. 106$110,2016$.

38. YUAN et al. Gray Matter Abnormalities Associated With Chronic Back Pain. The Clinical Journal of Pain, v.33, n.11, p.983-990, 2017.

39. WILLIAMS et al. Reliability and validity of a mobile tablet for assessing left/right judgements. Musculoskeletal Science and Practice, v.40, p.45-52, 2019. 


\section{APÊNDICE A - FICHA DE AVALIAÇÃo}

\section{Ambulatório de Reabilitação do Complexo do Ombro - ARCO}

Responsável pela avaliação:

Nome:
Data de nascimento:
Endereço Completo:
Telefone Fixo de Referência: ( )
Escolaridade: Nunca frequento Registro (Hygia):

Hipótese Diagnóstica Médica:

Peso (Kg): ___ Altura (cm): _____ Dominância Direita ( ) Esquerda ( ) Ambidestra ( )

Há quanto tempo tem dor no ombro (ou a quanto tempo o sintoma apareceu em um dos ombros)?

É no ombro DIREITO ( ) ESQUERDO ( ) ou AMBOS: ( ) O lado em que o sintoma é pior:

ANAMNESE (queixa principal, histórias, fatores de risco físico e outros):

Qual sua expectativa de melhora fazendo fisioterapia?

No último ano, quantas vezes procurou por médicos/outros por causa do seu ombro: Cirurgia previa no membro superior ou coluna? NÃO ( ) SIM ( ):

Alguma fratura no membro superior, pescoço ou tronco? NÃO( ) SIM ( ):

Alguma luxação no ombro, cotovelo ou mão? NÃO ( ) SIM ( ):

Dor irradiada pelo membro superior ou mãos? NÃO ( ) SIM ( ):

Tem doença sistêmica como diabetes, hipertensão, AR*? NÃO ( ) SIM ( )

Medicação para dor (Qual?/Dose?):

Exames complementares:

Está afastado do seu trabalho por causa da dor no ombro? NÃO ( ) **SIM ( ) meses Ocupação: Envolve alta demanda física ou psicológica NÃO( ) SIM( )

Sedentário ( ) ou Realiza atividade esportiva/prática corporal. Qual?

Tempo de prática: ______ (anos/meses) Frequência semanal de treino:

Treinamento de musculação ou outro? SIM ( ) NÃO ( ) Frequência Semanal: 
Você está com dor no ombro neste momento? NÃO（） SIM（）

Se SIM, qual é a intensidade da dor que está sentindo no ombro, agora, com o braço parado, em repouso, ao lado do corpo?

END - Assinalar a intensidade da dor usando um número inteiro, informar que $0=\operatorname{sem}$ dor; $10=$ pior dor

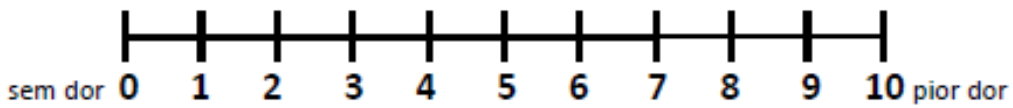

Você sente dor no ombro quando o braço está parado, em repouso? NÃO（） SIM（） NÃO SEI（）

\begin{tabular}{|c|c|c|}
\hline Quando você tem dor em repouso, a dor é: & $\begin{array}{l}1 \text { ( ) } \\
\text { contínua } \\
\text { estável }\end{array}$ & $\begin{array}{l}2(\text { ) } \\
\text { ritmada } \\
\text { periódica }\end{array}$ \\
\hline
\end{tabular}

Você sente dor no ombro a noite? NÃO（） SIM（） NÃO SEI（）

$\begin{array}{llll}\text { Quando você tem dor a noite, a dor é: } & 1() & 2() & 3(\text { ) } \\ & \text { contínua } & \text { ritmada breve } \\ \text { estável } & \text { periódica momentânea } \\ & \text { constante intermitente transitória }\end{array}$

Preencha no esquema de corpos qual(is) é(são) a(s) região(ões) que melhor representa(m) sua dor

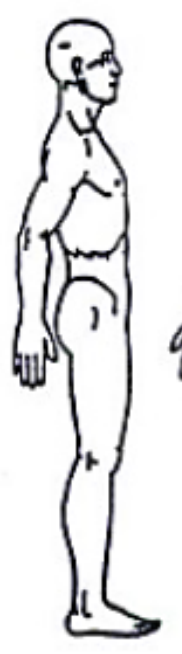

Lado Direito

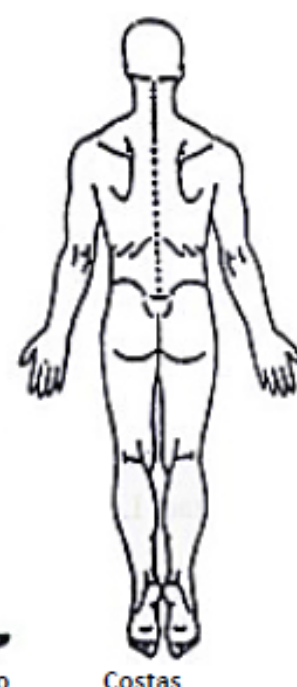

Costas

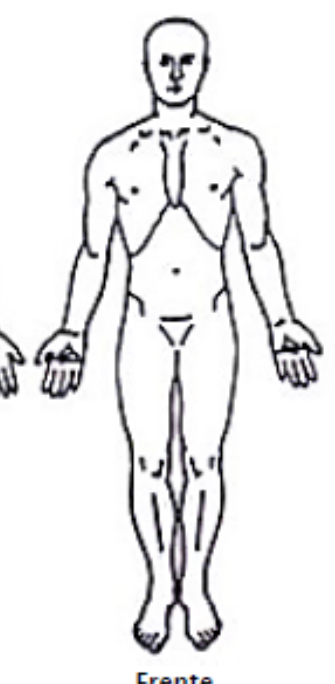

Frente

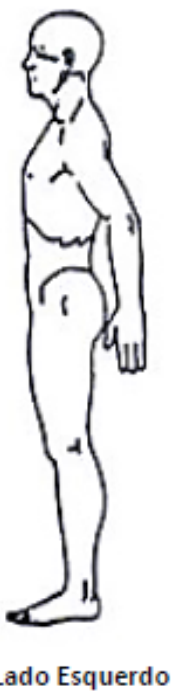




\section{APÊNDICE B - TERMO DE CONSENTIMENTO LIVRE E ESCLARECIDO}

O (a) Sr.(a) está sendo convidado a participar do estudo "Avaliação clínica da integridade somatossensorial em indivíduos com dor no ombro e um grupo controle" que será realizado na cidade de Ribeirão Preto - SP, tendo como responsáveis a Profa. Dra. Anamaria Siriani de Oliveira e a mestranda Amanda Matias Barbosa da Faculdade de Medicina de Ribeirão Preto - USP e como co-orientador Prof. Dr. Felipe Jose Jandre dos Reis, docente do Instituto Federal do Rio de Janeiro.

Esclarecimento geral e objetivo do estudo: O objetivo deste estudo será avaliar se sujeitos com e sem dor no ombro reconhecem o ombro direito e esquerdo e se são capazes de sentir dois pontos tocando a pele sem visualizar. Sabe-se que investigar mecanismos centrais da dor, pode auxiliar no tratamento e prognóstico das condições dolorosas no ombro. Acredita-se que os indivíduos com dor crônica apresentarão alterações no tempo de resposta e acurácia no teste de julgamento de lateralidade assim como na sensibilidade discriminativa quando comparados a indivíduos sem dor no ombro.

Explicação do procedimento: O Sr.(a) deverá assinalar a área de dor correspondente em um aplicativo que será apresentado através de um Tablet se for o caso do grupo com dor crônica. Em seguida, será realizado um teste, onde o Sr.(a), visualizará várias imagens do ombro e responderá se corresponde à direita ou à esquerda. Feito isso o Sr.(a) participará de outro teste, onde será aplicado um instrumento no seu ombro com duas pontas que não oferecem risco de lesão, e será questionado sobre a sensação.

Possíveis benefícios: A sua participação no estudo tem como possível benefício permitir que novas descobertas para pacientes com dor no ombro sejam investigadas e que podem ser usadas para melhorias no tratamento dos pacientes. O Sr.(a) terá garantia de acesso ao tratamento.

Desconforto e risco: A pesquisa poderá apresentar risco mínimo a sua saúde. O Sr.(a) poderá sentir um pouco de dor e desconforto após a avaliação sendo que esses sintomas desaparecerão aos poucos. De qualquer forma os pesquisadores estarão dispostos a solucionar problemas durante e após a realização da pesquisa. Os riscos destes procedimentos serão mínimos já que envolve apenas medições não invasivas.

Liberdade de participação: A sua participação neste estudo é voluntária. É seu direito interromper sua participação a qualquer momento, sem que isso cause qualquer penalidade ou prejuízo à sua pessoa, comprometendo-se somente a comunicar pelo menos um dos responsáveis da pesquisa.

Sigilo de identidade: Sua identidade será mantida em sigilo absoluto, as informações obtidas nesta pesquisa serão de maneira algumas associadas a sua identidade e não poderão ser consultadas por pessoas leigas sem sua autorização oficial. Estas informações poderão ser utilizadas para fins estatísticos ou científicos, desde que fiquem guardados a sua identidade e seu anonimato.

Ressarcimento de despesa e indenização: Pela sua participação, o Sr.(a) não receberá nenhum tipo de seguro de vida ou saúde que possa beneficiá-lo. Caso sinta-se prejudicado (a) ou lesado (a) por participar da pesquisa, o Sr.(a) deverá buscar indenização nas Leis 
vigentes no Brasil. Os responsáveis pelo estudo explicarão todos os riscos envolvidos, a necessidade da pesquisa e se prontificarão a responder todas as suas dúvidas.

O Sr.(a) recebera uma via deste documento assinado pelo participante e pelo pesquisador responsável. Se o Sr.(a) quiser saber quais são os resultados da sua avaliação o pesquisador responsável irá lhe entregar um relatório com os resultados.

$\mathrm{Eu}$, portador do $\mathrm{RG} \mathrm{n}^{\circ}$

Residente à

Bairro

Cidade declaro que tenho anos de idade e que concordo em participar, voluntariamente, na pesquisa conduzida pelos alunos responsáveis e por seu (sua) respectivo (a) orientador(a).

Nome Participante:

Data:

Assinatura Participante:

Nome Pesquisador:

Data:

Assinatura Pesquisador:

Esse estudo está sendo avaliado pelo Comitê de Ética e Pesquisa do Centro de Saúde Escola da Faculdade de Medicina de Ribeirão Preto.

Rua: Terezina, 690 Vila Maria Luiza

Telefone: 1633150009

Profa. Dra. Anamaria Siriani de Oliveira, Curso de Fisioterapia - Faculdade de Medicina de Ribeirão Preto - FMRP-USP: (16) 3315-4413 - siriani@fmrp.usp.br

Mestranda: Amanda Matias Barbosa, Pós-Graduação em Reabilitação e Desempenho Funcional - Faculdade de Medicina de Ribeirão Preto - FMRP-USP: (16) 98807-6527 - amanda.barbosa @usp.br 


\title{
ANEXO A - PARECER COMITÊ DE ÉTICA
}

\author{
CENTRO DE SAÚDE ESCOLA \\ FACULDADE DE MEDICINA DE RIBEIRÃO PRETO \\ UNIVERSIDADE DE SÃO PAULO
}

OF. 033/2017-CEP/CSE-FMRP-USP

Ribeirão Preto, 24 de Outubro de 2017.

Prezada Senhora

Comunicamos que o projeto de pesquisa abaixo especificado foi analisado $\mathbf{e}$ Aprovado "ad referendum "do Comitê de Ética em pesquisa do Centro de Saúde Escola da Faculdade de Medicina de Ribeirão Preto da Universidade de São Paulo, na data de 24 de Outubro de 2017.

CAAE: 76637517.0 .0000 .5414

Projeto de pesquisa: "Avaliação clínica da integridade somatossensorial em indivíduos com dor no ombro e um grupo controle"

Pesquisadora: Amanda Matias Barbosa

Em atendimento à Resolução 466/12, deverá ser encaminhado a este CEP o relatório final da pesquisa e a publicação de seus resultados, para acompanhamento, bem como comunicada qualquer intercorrência ou a sua interrupção.

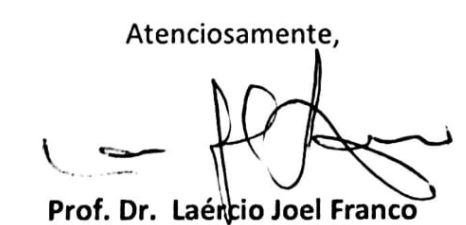

Coordenador do CEP/CSE-FMRP-USP.

IIma. Profa. Dra. Anamaria Siriani de Oliveira Docente do Departamento de Ciências da Saúde da Faculdade de Medicina de Ribeirão Preto/USP 


\section{USP - CENTRO DE SAÚDE ESCOLA DA FACULDADEDE Prationo MEDICINA DE RIBEIRÃO}

\section{PARECER CONSUBSTANCIADO DO CEP}

\section{DADOS DO PROJETO DE PESQUISA}

Título da Pesquisa: Avaliação clínica da integridade somatossensorial em individuos com dor no ombro $e$ um grupo controle.

Pesquisador: Amanda Matias Barbosa

Área Temática:

Versão: 2

CAAE: 76637517.0 .0000 .5414

Instituição Proponente: Centro de Saúde Escola - Faculdade de Medicina de Ribeirão Preto - USP

Patrocinador Principal: Financiamento Próprio

DADOS DO PARECER

Número do Parecer: 2.345.340

Apresentação do Projeto:

Resposta à pendência emitida 03/10/17 em relação ao TCLE.

Objetivo da Pesquisa:

Comparar os resultados dos testes de julgamento de lateralidade e discriminação de dois pontos para o ombro entre individuos com dor crônica no ombro e controles.

Avaliação dos Riscos e Benefícios:

Vide parecer anterior.

Comentários e Considerações sobre a Pesquisa:

Vide parecer anterior.

Considerações sobre os Termos de apresentação obrigatória:

As pendências em relação ao TCLEforam adequadamente atendidas.

Recomendações:

Não há.

Conclusões ou Pendências e Lista de Inadequações:

As pendências foram atendidas, de forma satisfatória.

Recomendo aprovar o projeto.

Endereço: TERESINA 690

Bairro: SUMAREZINHO

UF: SP Município: RIBEIRAO PRET

Telefone: (16)3315-0009

CEP: $14.055-380$

E-mail: csecuiaba@fmrp.usp.br 
1

\section{USP - CENTRO DE SAÚDE \\ ESCOLA DA FACULDADE DE MEDICINA DE RIBEIRÃO}

Continuação do Parecer: 2.345 .340

Considerações Finais a critério do CEP:

Projeto aprovado "ad referendum".

Este parecer foi elaborado baseado nos documentos abaixo relacionados:

\begin{tabular}{|c|c|c|c|c|}
\hline Tipo Documento & Arquivo & Postagem & Autor & Situação \\
\hline $\begin{array}{l}\text { Informaçōes Básicas } \\
\text { do Projeto }\end{array}$ & $\begin{array}{l}\text { PB_INFORMAÇŌES_BÁSICAS_DO_P } \\
\text { ROJETO 915213.pdf }\end{array}$ & $\begin{array}{c}20 / 10 / 2017 \\
11: 15: 11\end{array}$ & & Aceito \\
\hline $\begin{array}{l}\text { TCLE / Termos de } \\
\text { Assentimento / } \\
\text { Justificativa de } \\
\text { Ausência } \\
\end{array}$ & TCLE.docx & $\begin{array}{l}20 / 10 / 2017 \\
11: 14: 48\end{array}$ & $\begin{array}{l}\text { Amanda Matias } \\
\text { Barbosa }\end{array}$ & Aceito \\
\hline Outros & carta.docx & $\begin{array}{c}15 / 09 / 2017 \\
11: 11: 53\end{array}$ & $\begin{array}{l}\text { Amanda Matias } \\
\text { Barbosa }\end{array}$ & Aceito \\
\hline Outros & CAPP.pdf & $\begin{array}{l}15 / 09 / 2017 \\
11: 07: 29\end{array}$ & $\begin{array}{l}\text { Amanda Matias } \\
\text { Barbosa }\end{array}$ & Aceito \\
\hline $\begin{array}{l}\text { Projeto Detalhado I } \\
\text { Brochura } \\
\text { Investigador }\end{array}$ & mestrado.docx & $\begin{array}{l}08 / 08 / 2017 \\
12: 08: 40\end{array}$ & $\begin{array}{l}\text { Amanda Matias } \\
\text { Barbosa }\end{array}$ & Aceito \\
\hline Folha de Rosto & amanda.doc & $\begin{array}{c}08 / 08 / 2017 \\
12: 00: 33\end{array}$ & $\begin{array}{l}\text { Amanda Matias } \\
\text { Barbosa }\end{array}$ & Aceito \\
\hline
\end{tabular}

Situação do Parecer:

Aprovado

Necessita Apreciação da CONEP:

Não

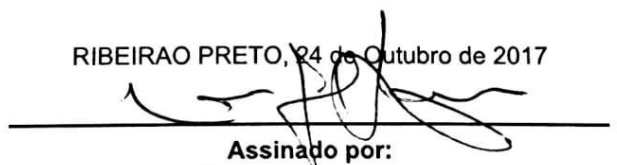

LAÉRCIO JOEL FRANCO

(Coordenador)

Endereço: TERESINA 690

Bairro: SUMAREZINHO

CEP: $\quad 14.055-380$

UF: SP Município: RIBEIRAO PRETO

Telefone: (16)3315-0009

E-mail: csecuiaba@fmrp.usp.br 


\section{ANEXO B - OFÍCIO SECRETARIA MUNICIPAL}

\section{Prefeitura Municipal de Ribeirão Preto sUS \\ Estado de Sào Paulo - Secretaria Municipal da Saúde}

OF.3046/2017- CAPP

$\mathrm{CV} / 2017$

Ribeirão Preto, 28 de julho de 2017.

Prezada Senhora,

Informo que a gerência da UBDS Sumarezinho - CSE Dr. Joel Domingos Machado da Secretaria Municipal da Saúde manifestou a concordância com a realização do projeto de pesquisa em sua Unidade.

Sendo assim, declaro estar ciente e concordo com a realização do projeto de pesquisa: "AVALIAÇÃO CLINICA DA INTEGRAÇÃO SOMATOSSENSORIAL EM INDIVÍDUOS COM DOR NO OMBRO E UM GRUPO CONTROLE" sOb a responsabilidade da Prof $^{a}$ Dra ANAMARIA SIRIANI DE OLIVEIRA, no local supra citado.

Informo que a pesquisa somente poderá iniciar quando obtiver a aprovação do Comitê de Ética em Pesquisa da instituição proponente.

Solicito que a pesquisadora encaminhe à Secretaria Municipal da Saúde o Relatório Final ao encerrar a pesquisa.

Cordialmente,

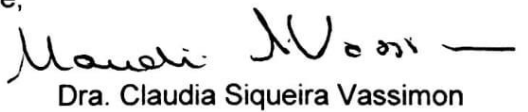

Coordenadora da Comissão de Avaliação de Projeto de Pesquisa da Secretaria Municipal de Saúde de Ribeirão Preto-CAPP

llustrissima Senhora

PROFa DRa ANAMARIA SIRIANI DE OLIVEIRA

COORDENADORA DO PROJETO DE PESQUISA

PROGRAMA DE RESIDÊNCIA MULTIPROFISSIONAL EM ATENÇÃO INTEGRAL À SAÚDE DA FACULDADE DE MEDICINA - USP

NESTA

Secretaria Municipal da Saúde

Comissão de Avaliação Projeto de Pesquisa

Av. Francisco Junqueira 1665, Centro, Ribeirão Preto

Fones: 39692205 / e-mail: capp@saude.pmrp.com.br 


\section{ANEXO C - SHOULDER PAIN AND DISABILITY INDEX (SPADI)}

Nome:

Braço avaliado: Data:

\section{SPADI - Escala de Incapacidade}

Os números ao lado de cada item representam o grau de dificuldade que você teve ao fazer aquela atividade. O número zero representa "sem dificuldade" e o número dez representa "Não conseguiu fazer". Por favor, indique o número que melhor descreve quanta dificuldade você teve para fazer cada uma das atividades durante a semana passada.

Se você não teve a oportunidade de fazer uma das atividades na semana passada, por favor, tente estimar qual número você daria para sua dificuldade.

\begin{tabular}{|c|c|c|}
\hline Lavar seu cabelo com o braço afetado? & ( ) NA & Sem dificuldade 012345678910 Não conseguiu fazer \\
\hline Lavar suas costas com o braço afetado? & ( ) NA & Sem dificuldade 012345678910 Não conseguiu fazer \\
\hline Vestir uma camiseta ou blusa pela cabeça? & ( ) NA & Sem dificuldade 012345678910 Não conseguiu fazer \\
\hline Vestir uma camisa que abotoa na frente? & ( ) NA & Sem dificuldade 012345678910 Não conseguiu fazer \\
\hline Vestir suas calças? & ( ) NA & Sem dificuldade 012345678910 Não conseguiu fazer \\
\hline $\begin{array}{l}\text { Colocar algo em uma prateleira alta com o } \\
\text { braço afetado? }\end{array}$ & ( ) NA & Sem dificuldade 012345678910 Não conseguiu fazer \\
\hline $\begin{array}{l}\text { Carregar um objeto pesado de } 5 \mathrm{~kg} \text { (saco } \\
\text { grande de arroz) com o braço afetado? }\end{array}$ & ( ) NA & Sem dificuldade 012345678910 Não conseguiu fazer \\
\hline $\begin{array}{l}\text { Retirar algo de seu bolso de trás com o } \\
\text { braço afetado? }\end{array}$ & ( ) NA & Sem dificuldade 012345678910 Não conseguiu fazer \\
\hline
\end{tabular}

SPADI - Escala de Dor

Os números ao lado de cada item representam quanta dor você sente em cada situação. O número zero representa "Sem dor" e o número dez representa "A pior dor". Por favor, indique o número que melhor descreve quanta dor você sentiu durante a semana passada em cada uma das seguintes situações.

Se você não teve a oportunidade de fazer uma das atividades na semana passada, por favor, tente estimar qual número você daria para sua dor.

\begin{tabular}{|l|c|c|}
\hline \multicolumn{2}{|l|}{ Qual a intensidade da sua dor quando foi a pior na semana passada? } & Sem dor 012345678910 Pior dor \\
\hline \multicolumn{2}{|l|}{ Durante a semana passada, qual a gravidade da sua dor: } \\
\hline Quando se deitou em cima do braço afetado? & ( )NA & Sem dor 012345678910 Pior dor \\
\hline $\begin{array}{l}\text { Quando tentou pegar algo em uma prateleira alta com o } \\
\text { braço afetado? }\end{array}$ & ( )NA & Sem dor 012345678910 Pior dor \\
\hline $\begin{array}{l}\text { Quando tentou tocar a parte de trás do pescoço com o } \\
\text { braço afetado? }\end{array}$ & ()NA & Sem dor 012345678910 Pior dor \\
\hline Quando tentou empurrar algo com o braço afetado? & ( )NA & Sem dor 012345678910 Pior dor \\
\hline
\end{tabular}

Total DOR _ _ _ _ possível $\times 100=$

PONTUAÇÃO TOTAL DO QUESTIONÁRIO: 
ESCALA DE AFETO NEGATIVO E POSITIVO - PANAS

\section{Instruções}

Este questionário é composto por palavras ou frases que descrevem diferentes modos de sentir ou de pensar sobre si mesmo. Leia cada item e, em seguida, assinale o número que vem ao lado direito da palavra que melhor caracteriza o seu modo de ser (determine aqui o espectro temporal que pret ende av aliar). Não há respostas certas ou erradas.

\begin{tabular}{|c|c|c|c|c|c|c|}
\hline & Item & Muito pouco/nada & Um pouco & Médio & Muito & Bastante/sempre \\
\hline 01 & Ativo & 1 & 2 & 3 & 4 & 5 \\
\hline 02 & Alerta & 1 & 2 & 3 & 4 & 5 \\
\hline 03 & Atento & 1 & 2 & 3 & 4 & 5 \\
\hline 04 & Com orgulho de si & 1 & 2 & 3 & 4 & 5 \\
\hline 05 & Determinado & 1 & 2 & 3 & 4 & 5 \\
\hline 06 & Entusiasmado & 1 & 2 & 3 & 4 & 5 \\
\hline 07 & Empolgado & 1 & 2 & 3 & 4 & 5 \\
\hline 08 & Inspirado & 1 & 2 & 3 & 4 & 5 \\
\hline 09 & Interessado & 1 & 2 & 3 & 4 & 5 \\
\hline 10 & Forte & 1 & 2 & 3 & 4 & 5 \\
\hline 11 & Com medo & 1 & 2 & 3 & 4 & 5 \\
\hline 12 & Envergonhado & 1 & 2 & 3 & 4 & 5 \\
\hline 13 & Aflito & 1 & 2 & 3 & 4 & 5 \\
\hline 14 & Culpado & 1 & 2 & 3 & 4 & 5 \\
\hline 15 & Hostil & 1 & 2 & 3 & 4 & 5 \\
\hline 16 & Irritável & 1 & 2 & 3 & 4 & 5 \\
\hline 17 & Inquieto & 1 & 2 & 3 & 4 & 5 \\
\hline 18 & Nervoso & 1 & 3 & 4 & 5 \\
\hline 19 & Apavorado & 1 & 3 & 4 & 5 \\
\hline 20 & Chateado & 1 & 3 & 4 & 5 \\
\hline
\end{tabular}




\section{ANEXO E - ESCALA DE PENSAMENTO CATASTRÓFICO SOBRE A DOR}

Escala de Pensamento Catastrófico sobre a Dor (B-PCS)

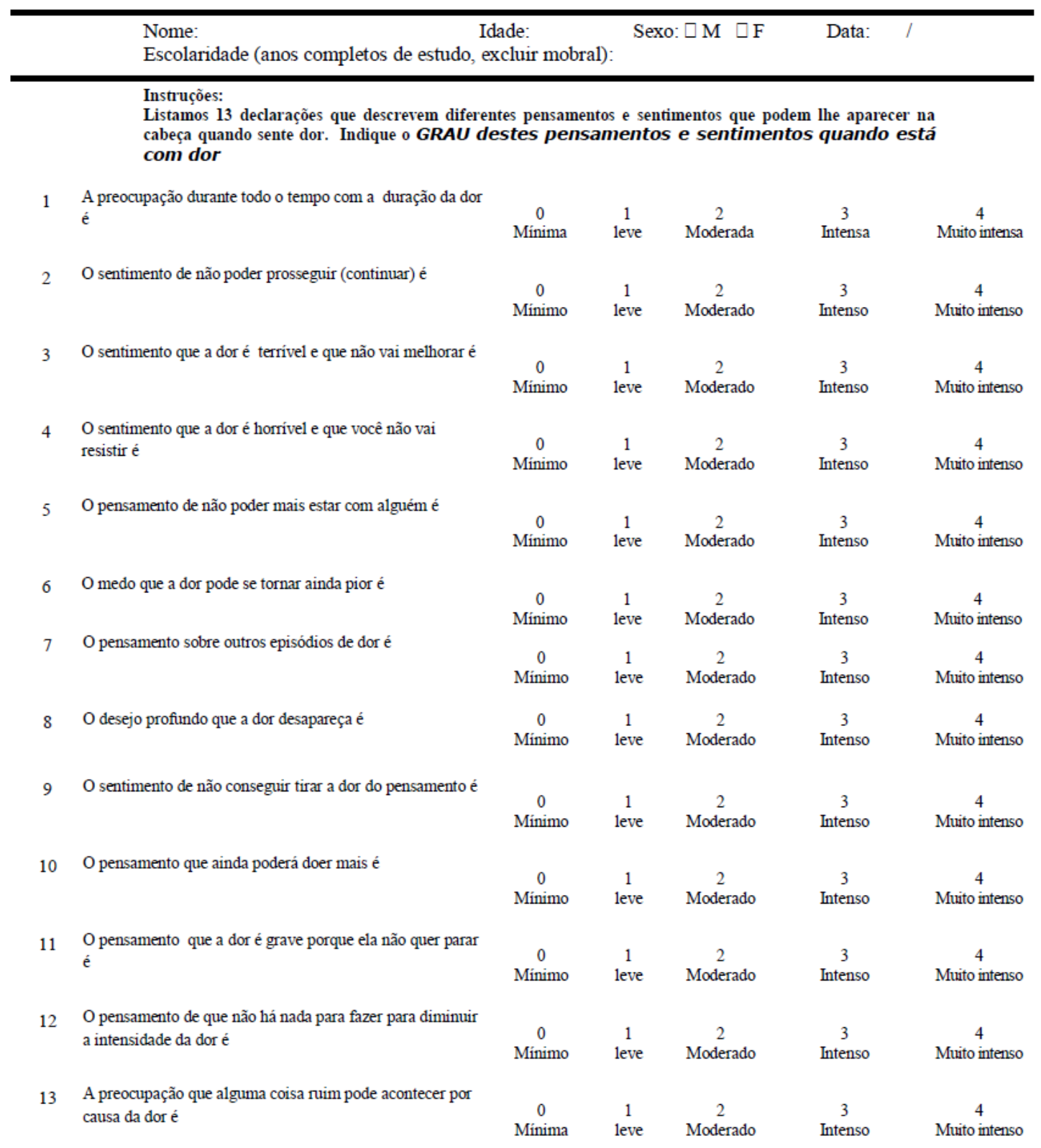

